\title{
CENTRO E PERIFERIAS COLONIAIS: O COMÉRCIO DO RIO DE JANEIRO COM SANTOS E RIO GRANDE (1802-1818)
}

\author{
Maximiliano M. Menz \\ Doutor pela Universidade de São Paulo/USP \\ Pós-dourorando - CEBRAP
}

\section{Resumo}

O artigo compara o comércio do Rio de Janeiro, capital do Brasil, com duas praças periféricas, Santos e Rio Grande entre 1802 e 1818. Pela análise da balança de comércio destes portos com o Rio de Janeiro, pretende-se revelar a hierarquia econômica e geográfica no interior da colônia e compreender sua relação com o comércio colonial português como um todo.

\section{Pallavras-Chave}

Sistema Colonial $\bullet$ Mercado Interno • Comércio

\section{Abstract}

This article compares the commerce of Rio de Janeiro, the Brazilian capital, with the peripherals ports of Santos and Rio Grande, between 1802 and 1818 . Through the analysis of commercial balance, we want to show the geographic and economic hierarchy within the colony and your relationship with the Portuguese colonial commerce.

\section{Keywords}

Colonial system $\bullet$ Internal Market $\bullet$ Commerce 
Até os anos 80 a historiografia brasileira sobre a colônia interpretou a formação do Brasil e a sua integração na economia mundial a partir do comércio exportador. Caio Prado Jr. foi um dos autores mais importantes na popularização desta idéia, pois em sua obra mais conhecida, Formação do Brasil Contemporâneo (1942), centrou no caráter exportador o sentido da colonização e da própria História do Brasil ${ }^{1}$.

Prado Jr. não chegou a desenvolver o problema da relação entre a economia exportadora e o comércio interior à colônia, mas Fernando Novais, o seu mais importante seguidor, condicionou a aparição de uma economia colonial de subsistência - com autonomia à grande lavoura - ao aumento na demanda externa $^{2}$. Novais era influenciado pela interpretação cepalina da história colonial latino-americana, especialmente de Celso Furtado ${ }^{3}$.

A influência cepalina na obra de Novais é um exemplo de como a historiografia brasileira nos anos 1950-70 seguia de perto os debates políticos e econômicos a respeito dos destinos do Brasil. Uma vez diagnosticada como de dependência a relação das economias latino-americanas com o centro do capitalismo mundial, propunha-se a industrialização como forma de superar esta relação; industrialização que deveria redundar na verdadeira independência do país ${ }^{4}$. Assim, o grande problema para os historiadores engajados neste debate era reconstituir as origens da própria dependência ${ }^{5}$.

${ }^{1}$ Cf. PRADO Jr. Caio. Formação do Brasil Contemporâneo. 20a ed. São Paulo: Brasiliense, 1986, pp. 19 e 31-32.

${ }^{2}$ Cf. NOVAIS, Fernando. Portugal e o Brasil na Crise do Antigo Sistema Colonial. $6{ }^{\mathrm{a}}$ ed., São Paulo: Hucitec, 1995, p. 96.

${ }^{3}$ Cf. a análise de Celso Furtado sobre a formação do complexo econômico nordestino (FURTADO, Celso. Formação Econômica do Brasil. 14ª ed. São Paulo: Cia. ed. Nacional, 1976, pp. 61-64).

${ }^{4}$ Como escreveu Mello: "As economias periféricas, enquanto dependentes, são mero prolongamento do espaço econômico das economias centrais e não se poderiam considerar como economias nacionais." (MELLO, João M. C. O Capitalismo Tardio. $4^{\text {a }}$ ed. São Paulo: Brasiliense, 1986, p. 21).

${ }^{5}$ Ribeiro Jr. começava um artigo sobre a Companhia de Comércio de Pernambuco formulando justamente esse problema: "Ao abordarmos um tema - companhia de comércio-(...) pensamos não perder de vista, na perspectiva da long a duração, um dos principais instrumentos condicionadores do atraso econômico dos países onde, por vários séculos, houve exploração colonial sistemática." (RIBEIRO Jr., José. As companhias coloniais no processo de acumulação originária: um estudo de caso (o nordeste brasileiro). In: Anais de História. no 8, (41-56), 1977). 
Nesse ambiente intelectual era natural que as questões específicas ao comércio no interior à colônia não fossem sequer postas. Um exemplo é o estudo sobre o comércio de cabotagem no Brasil de Maria Prado e Maria Luizetto; as autoras iniciam o texto realçando o caráter secundário deste comércio frente ao de exportação nos quadros do Antigo Sistema Colonial, em seguida apontam para o fato que apenas depois de 1808 a administração colonial mostrou-se interessada pelo setor. Sugeriam que somente com a vinda da família Real esta navegação teria tomado vulto ${ }^{6}$.

Nos anos 1980, contudo, começaram a surgir as primeiras críticas às insuficiências dos enfoques então dominantes. Historiadores vinculados a Maria Yeda Linhares publicaram diversos ataques à denominada "visão plantacionista" da História. Afirmavam assim que, para além da plantation, existiriam diversas formas camponesas ligadas à produção de alimentos para o "mercado interno colonial", entre estas, enumeravam: a "brecha camponesa" no sistema escravista, os lavradores subordinados aos senhores de engenho e os pequenos produtores do Sertão ${ }^{7}$.

Amaral Lapa, por sua vez, procurou agregar a idéia de um "mercado interno" na colônia ao conceito de sistema colonial. Em sua leitura, mercado interno se referia a um ou mais sistemas de trocas formados ao longo dos séculos XVI, XVII e XVIII, este mercado possuiria oscilações internas, relacionadas direta ou indiretamente com os mercados externos ${ }^{8}$. Para além da sugestão do caráter estrutural do mercado interno colonial (sua formação nos três séculos de colonização), o conceito foi tratado de forma bastante genérica, com o autor levantando poucas evidências empíricas que incluíam diferentes circuitos comerciais coloniais.

\footnotetext{
${ }^{6}$ PRADO, Maria L. e LUIZETTO, Maria C. Contribuição para o estudo do comércio de cabotagem no Brasil 1808-1822. In: Anais do Museu Paulista, T. XXX (159-196), São Paulo, 1980/1981, p. 160.

${ }^{7}$ LINHARES, Maria Y. e TEIXEIRA, Francisco C. História da Agricultura Brasileira: Combates e controvérsias. São Paulo: Brasiliense, 1981, p. 135, TEIXEIRA, Francisco C. Pecuária e formação do mercado interno do Brasil Colônia. In: GUTFREIND, Ieda e REICHEL, Heloisa. América Platina e Historiografia. São Leopoldo: PPGH UNISINOS, 1996 e CARDOSO, Ciro Flamarion S. Escravo ou Camponês? O protocampesinato negro nas Américas. São Paulo: Brasiliense, 1987, passim.

${ }^{8}$ LAPA, José R. A. O Antigo Sistema Colonial. São Paulo: Brasiliense, 1982, p. 45.
} 
Foi, no entanto, com a aparição de Homens de Grossa Aventura de João Fragoso e de O Arcaísmo como Projeto de João Fragoso e Manolo Florentino, no início dos anos 90, que o conceito de "mercado interno colonial" ganhou formulação teórica vigorosa e constituída sobre ampla pesquisa empírica; também foi nesses anos que o termo passou a ser referência obrigatória em trabalhos acadêmicos que tratassem da economia colonial.

Na visão de João Fragoso, era a própria reprodução da economia agroexportadora que gerava a demanda por abastecimento, derivando assim formas de produção não-capitalistas - mas mercantilizadas - no interior da própria colônia. Esta produção para o abastecimento produziria a acumulação de riquezas na colônia, acumulação esta que seria ditada pelo ritmo da demografia colonial, já que a demanda por alimentos é inelástica; seria a formação de um espaço colonial de acumulação na própria colônia - dominado por uma elite mercantil local-que permitiria uma certa autonomia à economia colonial frente às flutuações externas ${ }^{9}$.

Já no livro escrito em parceria com Manolo Florentino foi proposta uma interpretação alternativa ao paradigma do sentido da colonização. Por aí o mercado interno colonial passou a ser o centro do próprio mercado atlântico: não só o tráfico de escravos dependeria da demanda da colônia, como a própria importação de mercadorias européias estaria sob este ritmo. Os autores vão além e chegam a sugerir que a acumulação promovida pelo mercado interno colonial permitiu aos homens de negócio residentes no Rio de Janeiro controlarem uma parte expressiva do comércio com a Europa ${ }^{10}$.

Os trabalhos de João Fragoso deram origem a um grande número de teses preocupadas com o mercado interno colonial ${ }^{11}$. Enfim, buscaram constituirse numa interpretação alternativa à escola do "sentido da colonização". Entre-

\footnotetext{
${ }^{9}$ FRAGOSO, João L. Homens de Grossa Aventura. Acumulação e hierarquia na praça mercantil do Rio de Janeiro (1790-1830). 2a ed. revista, Rio de Janeiro: Civilização Brasilerira, 1998, resumimos argumentos das pp. 105-109, 119-120, 159, 179 e 291.

${ }^{10}$ FRAGOSO, João e FLORENTINO, Manolo. O Arcaísmo como Projeto. Mercado atlântico, sociedade agrária e elite mercantil em uma economia colonial tardia Rio de Janeiro, c. 1790 - c. $1840.4^{a}$ ed. revista. Rio de Janeiro: Civilização Brasileira, 2001, p. 111 et. passim. ${ }^{11}$ Por exemplo, SAMPAIO, Antonio C. O mercado carioca de crédito: da acumulação senhorial à acumulação mercantil. In:Estudos Históricos. 29, (29-49), Rio de Janeiro, 2002, e OSÓRIO, Helen. Estancieiros, Lavradores e Comerciantes na Constituição da Extremadura Portuguesa na América: Rio Grande de São Pedro, 1737-1822. Niterói: Tese de doutorado, UFF, 1999.
} 
tanto, surgiram trabalhos que, sem as mesmas preocupações teóricas e historiográficas de João Fragoso, Manolo Florentino e seus alunos, também contribuíram no estudo das relações comerciais internas à colônia, destaca-se aqui o texto pioneiro de Alcir Lenharo, ou as monografias mais recentes de Ilana Blaj e Junia Furtado ${ }^{12}$.

O presente trabalho tem por objeto o comércio entre a praça central do Rio de Janeiro e os portos periféricos de Santos e Rio Grande. Neste sentido, compartilha com esse movimento historiográfico mais recente da preocupação com as redes de comércio no interior da colônia. Não obstante, partimos de uma crítica ao uso do conceito de mercado interno colonial, pois, como escreve Ruggiero Romano, um mercado interno possui dimensões econômicas e geográficas que dificilmente poderiam ser encontradas na América Colonial, daí ser mais sensato falar em um comércio no interior das colônias que podia gerar um processo de agregação de diversos mercados regionais ${ }^{13}$. Além disto, acreditamos que a historiografia que vem estudando este "mercado interno" dá pouca atenção ao papel da reexportação de mercadorias européias na formação dos circuitos comerciais coloniais. A incorporação deste problema permite repensar a relação - de dependência - entre o comércio no interior da colônia e o sistema colonial como um todo. Ao cabo, quando realçamos os nexos hierárquicos entre o comércio colonial (exportador/importador) e seus circuitos internos, estamos nos aproximando do "ponto de vista" do sentido da colonização.

O contraste entre o comércio santista e o rio-grandense é pertinente porque expõe a complexa relação do mercado central no sul da colônia com as suas periferias. Como pretendemos demonstrar, duas economias supostamente "antagônicas" (exportadora, no caso de Santos, e de "mercado interno" no caso do Rio Grande) reproduziam-se sob as mesmas relações de dependência com o Rio de Janeiro; relações nas quais as mercadorias européias jogavam um papel central.

Nosso marco temporal abarca um período bastante conturbado nas relações entre metrópole e colônia (1802-1818). A opção por estes anos obedece às limitações

\footnotetext{
${ }^{12}$ LENHARO, Alcir. As Tropas da Moderação. São Paulo: Símbolo, 1979, BLAJ, Ilana. A Trama das Tensões. O processo de mercantilização de São Paulo colonial. São Paulo: Humanitas, 2002, FURTADO, Junia. Homens de Negócio: A interiorização da metrópole e do comércio nas minas setecentistas. São Paulo: Hucitec, 1999.

${ }^{13}$ ROMANO, Ruggiero. Mecanismo y Elementos del Sistema Económico Colonial Americano. Siglos XVI-XVIII. México: FCE, 2004, p. 342.
} 
impostas pelas fontes, somente depois de 1802 é que temos séries relativamente completas sobre o comércio interno à colônia, também há de se considerar que esses circuitos internos ganharam força com a crise do sistema colonial. Em todo o caso, se, por um lado, o intervalo estudado é de mudanças nos padrões do comércio colonial português, por outro, ele também é de permanências ${ }^{14}$.

Os dados aqui utilizados têm origem nas balanças de comércio realizadas pela Real Junta de Comércio na permanência da família Real no Rio de Janeiro ${ }^{15}$. Infelizmente, temos de lidar com uma série de insuficiências na análise destes números, seja a total inexistência de informações para alguns anos (1802-1809, 1813 para Santos e 1804, 1806, 1807, 1816 e 1817 para o Rio Grande), seja a ausência em alguns anos de dados pormenorizados que nos permitam avaliar a participação relativa das mercadorias européias no comércio interno.

\section{A praça de Santos e o comércio com o Rio}

A importância do Rio de Janeiro para o comércio santista é bastante óbvia, no período estudado (1810-1818, com a ausência de 1813) a capital do Brasil ${ }^{16}$ controlou 69,9\% do volume total de negócios, 57,7\% das exportações e 76,9\% das importações de Santos.

Comecemos pela análise das importações. Agrupamos os dados por valor em três tipos distintos de mercadorias: os produtos de provável origem européia, constando aqui tecidos, vinhos, ferramentas, metais, jóias, quinquilharias, etc.; em segundo lugar os gêneros da terra, como alimentos, sal, drogas, fumo e aguardente; na terceira coluna os escravos, por sua origem africana. É verdade que nesta classificação se escapam alguns produtos de origem asiática e africana, também pode ter ocorrido alguma confusão quanto à procedência de algumas

\footnotetext{
${ }^{14}$ Como já chamou a atenção Jorge Pedreira, depois do colapso de 1808, Portugal logrou recuperar entre 1814 e 1818 o papel de entreposto no comércio entre o Brasil e a Europa. Também houve no período uma ligeira recuperação na produção industrial portuguesa. (cf. PEDREIRA, Jorge. Estrutura Industrial e Mercado Colonial Portugal e Brasil (1780-1830). Lisboa: Difel, 1994, pp. 350-352, ver também ALEXANDRE, Valentim. Os Sentidos do Império: Questão nacional e questão colonial na crise do Antigo Regime português. Porto: Edições Afrontamento, 1993, pp. 772-773).

${ }^{15}$ AN, RJC, cx. 448, pct. 1.As únicas exceções são os anos de 1802, 1803 e 1805 que estão nos CDs do projeto Resgate (AHU - cx. 6, doc. 465, cx. 8, doc. 528 e cx. 11, doc. 668).

${ }^{16}$ Tratamos o Rio de Janeiro por "capital do Brasil” por ter sido a capital do Estado do Brasil (1763-1808) e a sede do Império Português (1808-1821).
} 
mercadorias, é o caso do sal que além de ser produzido nas salinas do nordeste era importado de Portugal. Acreditamos, porém, que estes problemas não inviabilizam a argumentação.

\begin{tabular}{|c|c|c|c|}
\hline \multicolumn{5}{|c|}{ Tabela I } \\
\hline Importações de Santos via Rio de Janeiro \\
\hline 1810 & Mercadorias européias & Gêneros da terra & Escravos \\
\hline 1811 & $83,6 \%$ & $6,6 \%$ & $9,8 \%$ \\
\hline 1812 & $85,3 \%$ & $6,0 \%$ & $8,8 \%$ \\
\hline 1814 & $85,1 \%$ & $6,5 \%$ & $8,4 \%$ \\
\hline 1815 & $78,2 \%$ & $8,7 \%$ & $13,1 \%$ \\
\hline 1816 & $83,3 \%$ & $5,2 \%$ & $11,5 \%$ \\
\hline 1817 & $65,4 \%$ & $5,8 \%$ & $28,8 \%$ \\
\hline 1818 & $79,1 \%$ & $3,9 \%$ & $17,0 \%$ \\
\hline Total & $68,2 \%$ & $4,8 \%$ & $27,0 \%$ \\
\hline
\end{tabular}

A tabela mostra que a maior parte das mercadorias importadas por Santos via Rio de Janeiro era de origem européia. O que se explica em primeiro lugar pela importância financeira da capital do Brasil, os homens de negócio desta praça obtinham facilmente mercadorias a crédito com os negociantes de Lisboa e de outros países, podendo então repassar vantajosamente os produtos europeus aos mercados periféricos. Em segundo lugar vêm as importações de escravos: o valor expressivo do comércio de escravos com o Rio deve-se ao pequeno fluxo de comércio direto entre a África e Santos. Ademais, ao menos desde o final do século XVIII, os mercadores do Rio de Janeiro dominavam a maior parte do resgate de negros em Angola, podendo fornecer cativos a preços competitivos na capitania de São Paulo. Por sua vez, a grande demanda por escravos era provocada por uma produção açucareira em ascensão - os preços mais que dobraram entre 1810 e 1818 - (ver também a tabela II). 
Por seu turno, as exportações eram menos variadas, ocorrendo um domínio total do açúcar:

\begin{tabular}{|c|c|c|}
\hline \multicolumn{3}{|c|}{$\begin{array}{c}\text { Tabela II } \\
\text { Exportações de açúcar de Santos para o } \\
\text { Rio de Janeiro }\end{array}$} \\
\hline Ano & \multicolumn{1}{c|}{ valor } & \% do total \\
\hline 1810 & $120: 271 \$ 100$ & 91 \\
\hline 1811 & $55: 040 \$ 000$ & 62 \\
\hline 1812 & $47: 686 \$ 000$ & 77 \\
\hline 1814 & $329: 381 \$ 600$ & 93 \\
\hline 1815 & $209: 607 \$ 600$ & 93 \\
\hline 1816 & $271: 022 \$ 000$ & 99 \\
\hline 1817 & $267: 589 \$ 500$ & 94 \\
\hline 1818 & $474: 997 \$ 900$ & 99 \\
\hline Total & $\mathbf{1 : 7 7 5 . 5 9 5 \$ 7 0 0}$ & $\mathbf{9 3}$ \\
\hline
\end{tabular}

Com exceção dos anos recessivos de 1811 e 1812, o valor do açúcar nunca ficou abaixo dos $90 \%$ do total. Estas exportações de açúcar naturalmente não eram para serem consumidas na capital; uma vez mais vemos a importância do Rio de Janeiro como centro de negócios do sul do Brasil; era ali que aportava a maioria das embarcações estrangeiras, facilitando os negócios com letras e crédito.

Viu-se como as importações de Santos no Rio excedem em termos relativos as exportações. Isto ocorre também em termos absolutos pois em todo o período a praça paulista acumulou um saldo negativo de mais de 2.187 contos de réis com a capital (média de 273 contos por ano), apenas no ano de 1818 houve superávit em razão de uma supersafra de açúcar.

Mas como Santos lograva saldar seus déficits com o Rio de Janeiro? Ora, se observarmos a balança de comércio santista como um todo, notaremos que esta praça acumula déficits sobre déficits seguindo a tendência das trocas com o Rio de Janeiro. Não obstante, não existem sinais de uma decadência econômica que comprovem uma suposta descapitalização da praça ${ }^{17}$.

Os constantes déficits só poderiam ser saldados se o porto de Santos estivesse fornecendo mercadorias para uma zona mais ampla, no interior da colônia. Neste sentido, o consumo de mercadorias européias significa em contrapartida

\footnotetext{
${ }^{17}$ Como escreveu Braudel: “(...) se o déficit se instala de modo permanente, é certa, num prazo mais ou menos longo, a deterioração estrutural de uma economia." (BRAUDEL, Fernand. Civilização Material, Economia e Capitalismo. Vol. 2, [O jogo das trocas]. São Paulo: Martins Fontes, 1998 p. 188). O déficit total no mesmo período (2.019 contos) é apenas um pouco menor do que o déficit com o Rio.
} 
a produção de uma renda no interior da própria capitania de São Paulo. Uma linha de raciocínio possível seria a proposta por Fragoso que fala de uma renda surgida nos mercados locais de abastecimento (no "mercado interno" paulista? $)^{18}$. Esta renda era obtida pelo abastecimento à grande lavoura; em última instância, portanto, a capacidade de compra dos produtores de gêneros alimentícios dependia das exportações de açúcar. O raciocínio é circular, pois como já foi mostrado, o comércio de açúcar não chegava nem perto de saldar as contas da praça. O negócio de mulas e de animais em pé com a capital deveria trazer numerário para São Paulo; este, porém, deveria ser um circuito bastante fechado, não haveria razão dos tropeiros adquirir mercadorias européias em Santos quando podiam comprar por melhores preços na capital.

Tudo indica que, apesar dos testemunhos constantes sobre a redução da produção aurífera, o ouro ainda tinha importância no comércio paulista. Afinal, no período estudado, o déficit de Santos com o Rio supera em 14,9\% as exportações para mesma praça e equivale a $66,3 \%$ de suas exportações totais. Como lembra Braudel, um déficit comercial pode temporariamente ser coberto por letras, mas se por acaso se mantém por muito tempo necessita ser pago em metálico $^{19}$. Ou seja, mesmo que a metade do déficit do período tenha sido coberto por letras (da própria praça do Rio de Janeiro, que corriam por todo o centro-sul e que provavelmente eram trazidas pelos tropeiros), as exportações de metais de Santos para a capital equivaleriam a mais da metade das outras exportações para o mesmo lugar ${ }^{20}$.

\section{A praça de Rio Grande e o comércio com o Rio}

Para o estudo do comércio do Rio Grande com a capital do Brasil possuímos uma série maior de dados, ainda que existam algumas lacunas e uma certa imprecisão nas importações de alguns anos. Incorporamos essas séries, pois iluminam uma série de questões relevantes.

\footnotetext{
${ }^{18}$ FRAGOSO, op. cit., p. 135-141.

${ }^{19}$ BRAUDEL, op. cit., p. 174.

${ }^{20}$ Infelizmente não existem dados sobre as remessas de numerário, mas os déficits acumulados podem ser uma boa indicação. Fisher, por exemplo, faz raciocínio parecido para calcular as remessas de ouro de Portugal para a Inglaterra (cf. FISHER, H. E. S. De Methuen a Pombal. O comércio anglo-português de 1700 a 1770. Lisboa: Gradiva, 1984).
} 
Nos anos entre 1802-1818 (com as já referidas exceções) o Rio Grande manteve com o Rio de Janeiro 65,3\% do total de seu movimento comercial; $57,4 \%$ das exportações se dirigiram para a capital e $73 \%$ das importações vieram de lá ${ }^{21}$. Temos assim um padrão de comércio muito semelhante ao de Santos.

Classifiquemos agora as importações sob o mesmo critério utilizado para Santos:

\begin{tabular}{|c|c|c|c|}
\hline \multicolumn{4}{|c|}{ Tabela III } \\
\hline Importações do Rio Grande via Rio de Janeiro ${ }^{22}$ \\
\hline Ano & $\begin{array}{c}\text { Mercadorias } \\
\text { européias }\end{array}$ & $\begin{array}{c}\text { Gêneros } \\
\text { da terra }\end{array}$ & Escravos \\
\hline 1802 & $79,2 \%$ & $13,2 \%$ & $7,5 \%$ \\
\hline 1803 & $65,5 \%$ & $22,1 \%$ & $12,5 \%$ \\
\hline 1805 & $77,0 \%$ & $14,8 \%$ & $8,2 \%$ \\
\hline 1808 & $64,2 \%$ & $22,8 \%$ & $13,0 \%$ \\
\hline 1809 & $79,4 \%$ & $12,0 \%$ & $8,7 \%$ \\
\hline 1810 & $70,4 \%$ & $19,9 \%$ & $9,7 \%$ \\
\hline 1811 & $68,6 \%$ & $15,2 \%$ & $16,2 \%$ \\
\hline 1812 & $75,3 \%$ & $14,5 \%$ & $10,2 \%$ \\
\hline 1815 & $69,0 \%$ & $14,4 \%$ & $16,6 \%$ \\
\hline Total & $\mathbf{7 2 , 2 \%}$ & $\mathbf{2 0 , 9 \%}$ & $\mathbf{2 4 , 1 \%}$ \\
\hline
\end{tabular}

Assim como o porto de Santos, Rio Grande tende a importar principalmente mercadorias européias do Rio de Janeiro. No geral as diferenças são desprezíveis, $72,2 \%$ do total das mercadorias importadas pelo Rio Grande no período eram européias, enquanto que a soma da série de Santos dá $78,3 \%$, outrossim, a inclusão dos anos 1802, 1803 e 1805 sugere que este padrão é anterior ao ano de 1808 . As diferenças aparecem quando comparadas as importações de gêneros da terra enquanto que em Santos elas são insignificantes - nunca alcançam os 10\%, no Rio Grande elas chegam a ser em 1808 mais que um $1 / 4$ do total e ultrapassam o valor dos escravos no

\footnotetext{
${ }^{21}$ As fontes tendem a sobrelevar o papel do Rio de Janeiro como consumidor e, por conseguinte, subestimar a participação das praças do Norte nas exportações rio-grandenses. Acontece que a capital do Brasil era um importante centro de informação das condições de mercado nas outras praças brasileiras; daí que muitos mestres de embarcações podiam declarar que partiam para o Rio de Janeiro, mas depois tomar outros destinos. Esta imprecisão não chega a alterar nossas conclusões.

${ }^{22}$ Não foi possível inserir os dados de 1813, 1814, e 1818, utilizados em outros cálculos porque as importações ou não estão discriminadas (1813) ou estão de maneira muito genérica $(1814$ e 1818$)$.
} 
cômputo geral ${ }^{23}$. A explicação é simples: o Rio Grande praticamente não produzia frutos tropicais, daí as importações significativas de aguardente de cana, tabaco e açúcar, também vale notar as constantes compras de sal, produto básico na produção do charque. Por último, parte expressiva desses gêneros da terra era negociada com os castelhanos na fronteira ${ }^{24}$. A compra de escravos no Rio vem em terceiro lugar; sua importância relativa era menor no Rio Grande do que em Santos. Mesmo assim, a média anual dos valores dispensados em escravos ultrapassa a da praça paulista (97 contos contra 81). Foi na década de 10 que se iniciou a montagem das manufaturas do charque (até então o fabrico de carne salgada era produção artesanal indissociável da estância), provocando forte demanda por cativos.

\begin{tabular}{|c|c|c|c|}
\hline \multicolumn{4}{|c|}{ Tabela IV } \\
Exportações do Rio Grande para Rio de Janeiro \\
\hline Ano & Charque & Couro & Trigo \\
\hline 1802 & $26,7 \%$ & $36,6 \%$ & $30,8 \%$ \\
\hline 1803 & $23,5 \%$ & $42,1 \%$ & $27,9 \%$ \\
\hline 1805 & $26,4 \%$ & $39,2 \%$ & $26,5 \%$ \\
\hline 1808 & $18,2 \%$ & $28,4 \%$ & $45,7 \%$ \\
\hline 1809 & $30,7 \%$ & $26,9 \%$ & $28,9 \%$ \\
\hline 1810 & $23,7 \%$ & $38,5 \%$ & $28,3 \%$ \\
\hline 1811 & $30,1 \%$ & $25,1 \%$ & 36,5 \\
\hline 1812 & $26,9 \%$ & $23,0 \%$ & $41,6 \%$ \\
\hline 1813 & $21,3 \%$ & $18,7 \%$ & $36,0 \%$ \\
\hline 1814 & $24,5 \%$ & $30,2 \%$ & $36,8 \%$ \\
\hline 1815 & $28,0 \%$ & $32,2 \%$ & $32,0 \%$ \\
\hline 1818 & $44,9 \%$ & $27,9 \%$ & $16,5 \%$ \\
\hline Total & $\mathbf{3 3 , 5 \%}$ & $\mathbf{2 9 , 0 \%}$ & $\mathbf{2 7 , 0 \%}$ \\
\hline
\end{tabular}
Também era considerável o número deles que eram reexportados para os domínios espanhóis.

A composição das exportações rio-grandenses é mais complexa do que as de Santos, merecendo uma análise mais pormenorizada. $\mathrm{Na}$ tabela IV separamos as três mercadorias mais importantes produzidas no Rio Grande, ao todo elas são quase $90 \%$ do total.

Os gêneros de consumo na própria colônia, charque e trigo, são quase $3 / 4$ do total das mercadorias

\footnotetext{
${ }^{23}$ É possível que isto se deva a uma escassez de mercadorias européias no ano de 1808 provocada pelo colapso do sistema colonial português.

${ }^{24}$ Cf. RACL. ALMEIDA, Luiz B. de G. Memória sobre a Capitania do Rio Grande do Sul. Ou influência da conquista de Buenos Aires pelos ingleses em toda a América e meios de prevenir seus efeitos, 1806, f. 55.
} 
enviadas para o Rio de Janeiro. O couro, produto que era reexportado para Europa, ocupa uma posição importante na pauta, especialmente no período anterior à chegada da família Real. Ainda que o trigo dependesse das colheitas, o seu percentual flutuava mais em relação à tendência dos preços, uma vez que o cereal era enfardado em couros seu valor deveria ser atrativo para concorrer com o preço da pele in natura; o ano de pico na série (1808) também é o ano de preço máxi$\mathrm{mo}^{25}$. É interessante notar que a participação do couro no total dependia muito mais da evolução dos outros produtos, já que o preço era determinado por peça, mantendo-se praticamente estável durante todo o período estudado ${ }^{26}$.

Pela importância dos gêneros da terra vê-se que as exportações rio-grandenses eram bastante distintas das de Santos. No entanto, no volume total de negócios com o Rio de Janeiro dos anos de 1802, 1803, 1805, 1808-1812 e 1815 as mercadorias européias e de exportação continuam sendo mais importantes $(56,1 \%)^{27}$, isto porque as importações que o Rio Grande fazia na capital eram sempre superiores às exportações. Para se ter uma idéia todas as exportações para o Rio de Janeiro superam em apenas uns 5\% as importações exclusivas de produtos europeus feitas na mesma cidade.

O problema dos déficits nos leva a estudar a balança do comércio do Rio Grande com o Rio de Janeiro. Calculando o saldo acumulado com todos os anos que possuímos (os mesmos utilizados na tabela IV) chegaremos a um saldo negativo de 2.377 contos, média de uns 198 contos por ano, um pouco menor do que a média de Santos. O que nos leva mais uma vez à pergunta de como eram saldadas estas contas.

Em linhas gerais pode-se dizer que os déficits do comércio com o Rio de Janeiro são saldados com superávits sobre a Bahia e Pernambuco. Estas praças

\footnotetext{
${ }^{25}$ As informações sobre os preços foram retiradas das balanças de comércio e confrontadas com FRAGOSO, op. cit. p. 279, tabela 14-1. Provavelmente se tivéssemos os anos de 1816 e 1817 a participação do charque no total seria ainda maior.

${ }^{26}$ Comparando séries incompletas da década de 1790, com os números de 1802, 1803 e 1805 vêse que, com exceção de 1802 quando era vendido em média por $\$ 800$, a peça era vendida por $1 \$ 000$ (AHU, docs. 252, 262, 465, 528). Nos anos seguintes vai variar entre $\$ 800$ e 1.200 , para além disso ocorrem algumas variações quando a fonte agrega ou deixa de agregar tipos diferentes de couros (por exemplo, o couro salgado ou o couro de égua). É interessante notar ainda que no Rio de Janeiro o preço desta mercadoria era acertado por peso, talvez um mecanismo de troca desigual.

${ }^{27}$ Para chegar a este número somamos as mercadorias européias importadas com os couros exportados. Os gêneros da terra, tanto importados como exportados eram 36,9\% e os escravos importados ficavam em 7,0\% do movimento geral do comércio.
} 
praticamente só compravam charque; já as importações rio-grandenses na Bahia eram muito parecidas com as do Rio, principalmente fazendas européias, mas também escravos e gêneros da terra, de Pernambuco se trazia produtos coloniais, em primeiro lugar o sal e depois o açúcar. O mais paradoxal é que é justamente com Pernambuco, a $3^{\text {a }}$ praça em importância nos negócios do Rio Grande, que a composição das trocas assemelha-se com um "mercado interno".

Mesmo assim, os saldos a seu favor com as praças do nordeste não chegam para cobrir os déficits com o Rio. E novamente a resposta é a mineração: o Rio Grande fornecia bestas para São Paulo e Minas e, de acordo com chanceler da Relação Luiz Beltrão de Gouveia d' Almeida, o negócio era todo saldado em ouro (41 contos para 1796) ${ }^{28}$. A esta afirmação os comerciantes replicaram dizendo que “(...) a maior parte daqueles tropeiros vêm a fazer suas tropas à sombra de imensos panos de algodão, de escravos adultos e viciosos, de abonos de homens estabelecidos na Capitania de São Paulo e de letras e ordens do comércio grosso do Rio de Janeiro (...)"29. De qualquer maneira não era o centro do país o principal fornecedor de numerário para o extremo-sul, pois a maior parte das moedas que corriam do sul para a capital eram de prata, como mostra a tabela V:

\begin{tabular}{|c|c|c|c|}
\hline \multicolumn{5}{|c|}{ Tabela V } \\
Moedas remetidas pelos comerciantes do Rio Grande ${ }^{30}$ \\
\hline Ano & $\begin{array}{c}\text { Pesos fortes } \\
\text { (convertidos em réis) }\end{array}$ & Réis & Total \\
\hline 1790 & $8: 730 \$ 000$ & $8: 047 \$ 000$ & $16: 777 \$ 000$ \\
\hline 1791 & $53: 391 \$ 000$ & $3: 494 \$ 000$ & $56: 885 \$ 000$ \\
\hline 1792 & $32: 637 \$ 750$ & $3: 556 \$ 075$ & $36: 193 \$ 825$ \\
\hline 1793 & $4: 722 \$ 000$ & $3: 400 \$ 000$ & $8: 122 \$ 000$ \\
\hline 1794 & $3: 684 \$ 750$ & $16: 386 \$ 065$ & $20: 070 \$ 815$ \\
\hline 1795 & $13: 374 \$ 750$ & $18: 332 \$ 300$ & $31: 707 \$ 050$ \\
\hline Total & $\mathbf{1 1 6 : 5 4 0 \$ 2 5 0}$ & $\mathbf{5 3 : 2 1 5} \$ \mathbf{4 4 0}$ & $\mathbf{1 6 9 : 7 5 5} \$ \mathbf{6 9 0}$ \\
\hline
\end{tabular}

${ }^{28}$ In: AHRS, AG, B-1.03. Rodrigo de Souza Coutinho, 26/07/1802.

${ }^{29}$ Memorial da câmara da Vila de Porto Alegre. In: RIHGRS, 128, Porto Alegre, 1992, p. 159. Os memorialistas falavam de uma exportação de animais em pé no valor de 74 contos para o ano de 1803.

${ }^{30} \mathrm{BN}, \mathrm{I}, 29,19,28$. Neste documento só constam as exportações. Não está declarado o destino dessas moedas, mas os dados de 1802, 1803 (em que existem as remessas, mas não estão declaradas as quantidades de prata) mostram que a maior parte do envio de metálico era para o Rio de Janeiro. 
Do total do envio de moedas os pesos castelhanos eram mais que o dobro do valor em réis. O dinheiro castelhano corria para o Rio Grande em troca de escravos, fumo, cachaça e, especialmente nos momentos de convulsão no tráfico espanhol, mercadorias européias; também era comum o jogo das duas moedas ${ }^{31}$.

Portanto, ao contrário do que sugeria uma análise superficial da balança de comércio, no total, o comércio do Rio Grande tendia a ser superavitário. Isto explica a capacidade da economia rio-grandense em responder à demanda dos centros coloniais na metade da década de 10 do século XIX.

Importa fixar aqui que estes fluxos financeiros normalmente seguiam para o Rio de Janeiro ${ }^{32}$. Neste sentido, os déficits podem indicar em parte o valor das remessas de metais; aceitando mais uma vez que metade do déficit era saldada em metais, teríamos um envio médio de quase 100 contos por ano ${ }^{33}$.

\section{Formulando um padrão para os circuitos internos coloniais}

Analisadas as relações comerciais das praças de Santos e do Rio Grande em suas particularidades, resta fazer as comparações devidas que nos permitam definir um padrão para os circuitos internos coloniais, ao menos no que diz respeito ao centro-sul do início do século XIX:

1) A importância das mercadorias européias na formação dos circuitos: É muito claro que eram as mercadorias importadas da Europa pelo Rio de Janeiro que

${ }^{31} \mathrm{Cf}$. as expressivas remessas de ouro pelo Rio da Prata em ASDRÚBAL SILVA, Hernan. El Comercio entre España y el Río de la Plata (1778-1810). s/l: Banco de España, 1993, p. 33. Para uma lista de mercadorias que poderiam ser vendidas aos espanhóis, com os respectivos preços, cf. AHRS, AM, M-22, 01/07/1810, Thomas da Costa Correa Rebello e Silva.

${ }^{32}$ São comuns os testemunhos sobre a desmonetização na capitania do Rio Grande, ver por exemplo: AHRS, AG, B-1.03, 16/09/1801, Conde de Resende e AAHRS, Vol. 12, pp. 181182, 30/03/1805, Paulo José da Silva Gama.

${ }^{33}$ Quando tratávamos de Santos já fizemos as considerações necessárias sobre a relação entre saldos e remessas financeiras. Não obstante, a existência de informações precisas sobre os envios de dinheiro do Rio Grande para o Rio nos anos de 1802 e 1803 permite verificar na prática essa relação: em 1802 o déficit com o Rio de Janeiro chegou a 189 contos e foram remetidos 84 contos em moeda. No ano seguinte o Rio Grande atingiu um superávit de 55 e poucos contos e mandou mais uns 46 contos em dinheiro. O resultado de 1803 , mais as remessas de numerário chegam a quase 186 contos, muito perto de saldar o déficit de 1802 . Outro cálculo interessante: enquanto que no período entre 1790-1795 as remessas de moeda são, em média, 7\% do total das exportações do período, o déficit com o Rio de Janeiro calculado para 1802-1818 é 15\% do total das exportações; ou seja, se a metade deste saldo fosse coberto por moedas chegaríamos a uma proporção muito próxima do período anterior. 
formavam os circuitos, pois eram as bases das importações do Rio Grande e de Santos. Elas funcionavam como crédito e, assim, podiam dinamizar a economia de regiões que até então eram irrelevantes, como o extremo-sul até 1780 . Como a capital do Brasil obtinha estes produtos europeus - ao menos até 1808 - pela sua relação privilegiada com Lisboa, a força de atração do seu mercado deve ser explicada, em primeiro lugar, pela sua posição no Império e não pela existência de um suposto mercado interno. É natural, portanto, que o vice-rei se mostrasse contrariado com as idéias do governador de São Paulo que projetava incentivar o comércio direto entre Santos e Lisboa ${ }^{34}$.

2) A formação de um fluxo de metais preciosos da periferia para o centro: As regiões periféricas pagavam as importações de mercadorias com produtos variados, gêneros da terra, produtos demandados na Europa e metais preciosos. A hierarquia de cada tipo de mercadoria variava em cada praça, porém, é impossível negar que tanto Santos como Rio Grande enviavam muitos metais para o Rio. Ora, era com as moedas obtidas em suas regiões periféricas que a capital saldava suas contas deficitárias com Portugal (ao menos até 1808). Para se ter uma idéia da magnitude dos valores, de 1796 a 1807 o Rio de Janeiro enviou em metálico 16.059 contos para a Metrópole, média de 1.302 contos por ano ${ }^{35}$.

3) A oferta de mercadorias como elemento central do comércio nas regiões periféricas: Como a moeda pouco circulava nas periferias coloniais e as mercadorias funcionavam como crédito, pode-se dizer que, em última análise, a demanda nestas regiões era secundária para o fechamento dos circuitos mercantis. Nas palavras dos homens de negócio do Rio Grande: “(...) suposto abunde o País em gêneros importados por gêneros exportados

\footnotetext{
${ }^{34}$ AN, NP, Cód. 68, vol. 9, 24/07/1791, Conde de Resende. Apesar destas tentativas do governador paulista o Rio de Janeiro manteve o domínio sobre a praça de Santos. É provável que para os mercadores de Lisboa fosse mais seguro deixar os mercados periféricos para a capital do Brasil, socializando os lucros, mas também os riscos.

${ }^{35}$ Em troca vieram uns 374 contos, uns 31 contos por ano (ARRUDA, José Jobson de. $O$ Brasil no Comércio Colonial. São Paulo: Ática, 1980. tabela 19). . “(...) mais da metade das moedas metálicas cunhadas pela Casa da Moeda do Rio de Janeiro, todos os anos, era retirada da circulação, pois era conduzida para Lisboa." (SANTOS, Corcino M. Relações Comerciais do Rio de Janeiro com Lisboa (1763-1808). Rio de Janeiro: Tempo Brasileiro, 1980, p. 193). É verdade que parte desta desmonetização da própria capital devia-se ao pagamento de impostos para o Rei.
} 
é estéril demanda porque a pouca que corre é exaurida pelas efetivas remessas, que os comerciantes do Continente fazem aos seus credores dos referidos portos do Brasil." ${ }^{\text {36 }}$. Ou seja, o mercador, o fazendeiro e o peão na periferia tinham pouco poder de escolha em suas compras porque o metálico não ficava em suas mãos; havia claramente uma hierarquia no poder de escolha que acompanhava a hierarquia do crédito $^{37}$.

4) A importância residual dos circuitos de metais: Parece que, ao menos até 1808, o circuito tradicional de metais (das periferias coloniais para o Rio de Janeiro, do Rio de Janeiro para Lisboa) tinha ainda alguma importância. A proximidade com os locais de produção aurífera ou argêntea permitia a algumas praças periféricas saldar suas contas com a capital. É verdade que depois de 1808, com a dissolução de parte deste circuito, os metais tendiam a ficar mais tempo na colônia, alimentando o giro do comércio $^{38}$.

Sendo assim, este estudo demonstrou o caráter estruturante das mercadorias européias na formação dos circuitos mercantis no interior da colônia e a sua relação com a drenagem de moedas coloniais. Estes circuitos reproduziam uma hierarquia entre diferentes praças do Império português, na qual o Rio de Janeiro, através de mercadorias importadas de Lisboa, articulava as regiões centrais da economia mundo com algumas regiões periféricas do Brasil. Por essa análise, portanto, fica reforçada a interpretação do sentido da colonização ao mesmo tempo em que se aponta para a insuficiência do conceito de "mercado interno colonial". Por outro lado, a importância desses circuitos para a reprodução do nexo colonial permite (re)problematizar a dependência pelos seus mecanismos mercantis internos.

\footnotetext{
${ }^{36}$ Memorial da câmara da Vila de Porto Alegre. In: RIHGRS, 128, Porto Alegre, 1992, p. 159.

${ }^{37}$ Teríamos assim um movimento centrífugo do crédito que por sua vez reproduzia e era reproduzido por um movimento centrípeto das moedas e metais preciosos.

${ }^{38}$ Em Portugal começaram a surgir manifestações sobre uma inversão do circuito de metais entre colônia e metrópole ( $c f$, por exemplo a queixa dos negociantes portugueses citada por ALEXANDRE, op. cit,. p. 403. A inversão pode explicar em parte a descolagem da economia brasileira frente à conjuntura européia no pós - 1815; assim, ao contrário do que diz João Fragoso, não seria o mercado interno colonial que explicaria o comportamento ascendente dos preços brasileiros, mas sim o aumento na velocidade de circulação de moedas (cf. FRAGOSO, op. cit. p. 270, MAURO, Frédéric. A Conjuntura atlântica e a Independência do Brasil. In: MOTTA, Carlos G. (org.). 1822 Dimensões. (38-47). São Paulo: Perspectiva, 1972, ver também KLEIN, Herbert S. e ENGERMAN, Stanley J. Methods and meanings in proce history. In: JOHNSON, Lyman L. e TANDETER, Enrique. Essays on the Price History of Eighteenth-Century LatinAmerica. (9-20). Albuquerque: University of New Mexico Press, 1990, p. 17).
} 